\title{
Sete novelas a procura de um tradutor: a aventura de Corpo de baile na França
}

\author{
Seven tales in search of a translator: the adventure of Corpo de baile in French
}

\author{
Márcia Valéria Martinez de Aguiar
}

Universidade de São Paulo/FAPESP - São Paulo - São Paulo - Brasil

\begin{abstract}
Resumo: A preparação das notas da correspondência trocada entre João Guimarães Rosa e seu tradutor francês, Jean-Jacques Villard, está nos levando a ampliar a compreensão da tradução e da recepção da obra do escritor nos anos 1960 na França. Um dos aspectos desse processo que sempre nos intrigara, e que as cartas trocadas entre o escritor e seu tradutor não eram capazes de esclarecer, dizia respeito ao modo como se estabelecera o contato entre eles. A investigação que empreendemos a partir do nome de Michel Chodkiewicz, editor da Seuil responsável pela publicação das obras de Guimarães Rosa junto a essa editora, levou-nos não só a responder a essa questão, como a entender o papel fundamental que o compromisso pessoal de um editor para com uma obra representara para a publicação de Corpo de baile na França dos anos 1960.
\end{abstract}

Palavras-chave: Guimarães Rosa; Recepção; Tradução; Correspondência; Editor

\begin{abstract}
The preparation of the notes to the correspondence exchanged between João Guimarães Rosa and his French translator Jean Jacques Villard has taken us to enlarge our understanding of the reception and translation of the writer's work in France during the sixties. One of the points of that process which has always aroused in us a certain perplexity, and that the letters between the writer and his translator were not able to clarify, was about how they got in touch with each other. The inquiry we undertook from the name of Michel Chodkievicz, Seuil's publisher, responsible for the printing of João Guimarães Rosa's works, has taken us not only to answer that question, but also to understand the fundamental role that a publisher's personal commitment to a work played in the publishing of Corpo de Baile in France in that time.
\end{abstract}

Keywords: Guimarães Rosa; Reception; Translation; Correspondence; Publisher

\section{Apresentação}

Há mais de quarenta anos, Paulo Rónai já apontava a importância da correspondência de Guimarães Rosa com seus tradutores para a compreensão da obra do escritor. "Se", diz ele, "o escritor recusava sistematicamente a satisfazer a curiosidade profissional dos repórteres, encontrava sempre disposição para atender as consultas de seus tradutores" (RÓNAI, 1971), o que faz com que suas respostas representem, continua ele, "uma exegese minuciosa da obra roseana pela única pessoa capaz de dá-la" (RÓNAI, 1971).

A distância que hoje nos separa das primeiras publicações de Guimarães Rosa no exterior, faz com que essas cartas contribuam também para desenhar o universo de recepção de seus livros na Europa e nos Estados Unidos ao longo dos anos 1960, pois as pessoas, instituições e acontecimentos que as povoam permitem que se reconstitua o cenário dessa recepção.

Essa tem sido a nossa experiência com a edição e a confecção de notas para a correspondência de João Guimarães Rosa com seu tradutor francês, Jean-Jacques Villard, que preparamos para futura publicação. Esse trabalho está nos levando a esclarecer aspectos obscuros do lançamento de Corpo de baile na França, por meio do exame do papel que representaram, nesse processo, os diferentes personagens que dele participaram.

Uma dessas zonas de sombra nos intrigava há tempos: como Jean-Jacques Villard se tornara o tradutor de Guimarães Rosa? Começaremos por descrever a relação que se trava entre eles ao longo de sua correspondência para, em seguida, retraçar os passos que levaram ao encontro do autor com esse tradutor. Tal percurso nos levará a reconstituir uma parte fundamental da cena de 
publicação de Corpo de baile na França dos anos 1960. E a apontar o papel decisivo que nela desempenharam dois atores: uma editora, a Seuil, e um editor, Michel Chodkiewicz.

\section{Cena principal: autor e tradutor}

49 cartas compõem a correspondência entre Guimarães Rosa e Jean-Jacques Villard, que teve início em 1961 e só terminou com a morte do escritor em 1967¹. Guimarães Rosa, desde a primeira carta que escreve a Villard, em 27 de julho de 1961, manifesta a sua admiração pelo trabalho desse tradutor, cujo "esplêndido talento", afirma ele, possibilitara a publicação, em 1961, de seu primeiro livro lançado em uma língua estrangeira, Buriti. O volume, que continha três novelas de Corpo de baile - "Dão-lalalão", "O recado do morro" e "A festa de Manuelzão" - estava agora, alegra-se o escritor, "entregue ao mundo grande".

Nessa mesma carta, Guimarães Rosa destaca passagens que lhe parecem obtidas "de modo milagroso, ou por artes de alguma feitiçaria", como a estória do Boi Bonito da "Festa de Manuelzão":

Tudo é preservado: ritmos, rimas, assonâncias, variações de velocidade, o tom regional e o gosto arcaico! (Aliás, com a mesma admirada emoção vi como traduziu todas as partes em verso, as quadras.) O meu Amigo trabalhou a carne e a sombra das coisas, os cernes e as espumas - tudo com a mesma agudez amorosa. Um trabalho de amor, a gente vê. Agora, estaremos juntos, enfrentando esses destinos. (JGR a JJV, 27/07/1961)

Do mesmo modo aplaude, no ano seguinte, Les nuits $d u$ sertao, cujas dificuldades haviam sido "todas vencidas com maestria" por Villard que fizera uma tradução "boa, cuidada, competente, conseguida, fiel e viva - a melhor possível" (JGR a JJV, 17/10/1962). E não esconde seu contentamento por ter encontrado tal intérprete:

Sei como é importante, às vezes decisivo, a gente ter a sorte de encontrar um tradutor excepcional, capaz de traduzir "com alma" nossos livros. Sei que tive essa extraordinária sorte. Sei, também, que os demais livros, inclusive o "GRANDE SERTÃO: VEREDAS" não poderiam estar em melhores mãos. (JGR a JJV, $17 / 10 / 1962)$

\footnotetext{
O Fundo João Guimarães Rosa do Instituto de Estudos Brasileiros da Universidade de São Paulo conserva 47 cartas dessa correspondência. As duas outras pertencem à família do tradutor. Nas citações, usaremos as abreviaturas JGR e JJV respectivamente para o autor e o tradutor. Optamos por traduzir diretamente as passagens das cartas de Jean-Jacques Villard citadas no corpo do texto, deixando-as no original, seguidas de tradução, quando aparecem em parágrafo separado. Seguimos esse procedimento também para com outros correspondentes de Guimarães Rosa citados neste artigo.
}

O homem que conseguira cativar assim Guimarães Rosa declara, por sua vez, estar em uma espécie de comunhão de espírito com o escritor, a ponto de se sentir amputado, diz ele, "de uma parte de mim mesmo, talvez da melhor", ao acabar uma tradução do autor. As estórias de Guimarães Rosa haviam-lhe permitido, a ele, que mal conhecia o Brasil, de se integrar a esse país, que considerava um pouco seu:

Peut-être nos esprits sont-ils pour ainsi dire en communion et que c'est cela qui me permet de vous bien comprendre et d'aimer ce que vous aimez. Mon grand regret est de si peu connaître le Brésil, n'ayant fait qu'une brève escale à Rio en 1921, mais maintenant j'ai l'impression d'avoir vécu des années sur les rives du S. Francisco, de l'Abaeté, dans la région de l'Urucuia, que j'ai suivi des boiades, bu le vin de buriti, et je ne puis vous exprimer ma reconnaissance pour m'avoir procuré ce sentiment. (JJV a JGR, 29/10/1962)

Talvez nossos espíritos estejam, por assim dizer, em comunhão, e que seja isso que me permita entendêlo perfeitamente e amar o que você ama. O que mais lamento é conhecer tão pouco o Brasil, só tendo feito uma breve escala no Rio em 1921, mas agora tenho a impressão de ter vivido anos às margens do São Francisco, do Abaeté, na região do Urucuia, que acompanhei boiadas, bebi o vinho de buriti, e não posso exprimir-lhe meu reconhecimento por ter-me proporcionado esse sentimento.

E trata ele próprio de se apresentar ao escritor no transcorrer de sua correspondência. Filho de mãe brasileira, vivera na casa dos avôs em Paris "em uma atmosfera puramente brasileira, que me permitiu aprender a língua e conhecer os costumes" (JJV a JGR, 07/09/1961). Estudara em dois dos melhores colégios de Paris, o Lycée Carnot e, depois, o Lycée Henri IV, e dominava várias línguas estrangeiras - alemão, inglês, português, holandês e espanhol, além de grego e latim.

Lutou nas duas guerras mundiais, e a experiência das trincheiras da Primeira Guerra o marcou profundamente. Ao longo das cartas, relata a Guimarães Rosa alguns episódios entre curiosos e macabros, como a estória do velho soldado que queria guardar como lembrança o braço de "unhas bem feitas" de um soldado alemão que encontrara no meio de cadáveres em putrefação; ou o caso do tenente que teve um acesso de loucura ao ver todos os seus homens morrerem na explosão de um abrigo sabotado pelos alemães e que insistia em ali permanecer, ignorando os gases venenosos, pois queria jantar com eles (cf. JJV a JGR, 24/06/1963).

Aliás, a veia narrativa de Jean-Jacques Villard revelase muitas vezes em suas cartas ao escritor, nas quais descobrimos estórias dos camponeses normandos, com sua tacanhez ora cômica ora bruta, contadas em um estilo 
que não deixa de evocar, como nota o próprio Guimarães Rosa, as novelas de Maupassant (cf., por exemplo, JJV a JGR, 05/10/1963 e JGR a JJV, 14/10/1963). O tradutor relata, também, anedotas envolvendo seu irmão mais novo. Este último, que se mudara para o Brasil, tivera que, um dia, para fazer-se respeitar pelos homens sob o seu comando em uma fazenda, bancar o grande macumbeiro, recitando estranhas palavras em uma suposta língua de magia, que não passava, afinal, conta-nos Villard, dos primeiros versos em latim da Eneida de Virgílio, que ele sabia de cor (cf. JGR a JJV, 01/05/1963).

Esse gosto pelas narrativas deve sem dúvida ter contribuído para o seu sucesso como tradutor, atividade que iniciou casualmente e que acabou se tornando uma profissão:

Ma grande occupation est de traduire. Cela avait commencé comme un "hobby" en 1956, c'est presque devenu une profession aujourd'hui. En 8 ans j'ai traduit 23 livres, sans compter diverses brochures, de l'anglais, de l'allemand, du hollandais, du portugais, j'ai lu et fait la critique de centaines de romans de ces langues, plus certains en espagnol. Ça me passionne, mais jamais je n'ai éprouvé une joie si grande qu'à traduire vos oeuvres qui me permettent de vivre sous un autre climat, dans un pays que je me prends à aimer comme si c'était le mien... et au fond il l'est un peu. (JJV a JGR, 12/11/1963)

Minha grande ocupação é traduzir. Tudo começou como um "hobby" em 1956 e hoje quase se tornou uma profissão. Em oito anos, traduzi 23 livros, sem contar diversas brochuras, do inglês, do alemão, do holandês, do português, li e fiz a crítica de centenas de romances dessas línguas, além de alguns em espanhol. Acho isso apaixonante, mas nunca experimentei tão grande alegria como ao traduzir suas obras, que me permitem viver em outro clima, em um país que me pego a amar como se fosse o meu... e, no fundo, ele não deixa de ser um pouco.

Esse "casamento feliz" entre autor e tradutor, para retomar a expressão de Guimarães Rosa (JGR a JJV, 09/05/1963), acabou por ampliar, aos nossos olhos, a zona de sombra que existe nessas cartas. Ao contrário da correspondência do escritor com seus outros intérpretes, as cartas com Jean-Jacques Villard não se iniciaram antes que ele traduzisse seu primeiro livro do autor, mas apenas depois. Desse modo, se sabemos, por exemplo, que foi Harriet de Onís, tradutora americana de Grande sertão: veredas e Sagarana, quem apresentou seu nome para a editora Knopf, e que foi Curt Meyer-Clason, tradutor alemão de Grande sertão: veredas e Primeiras estórias, quem lutou pela publicação dessas obras na Alemanha, pois ambos, antes de traduzi-lo, tinham conhecido e se apaixonado por sua literatura, nada sabemos do modo como se deu o encontro entre Guimarães Rosa e JeanJacques Villard. Esse enigma só nos foi desvendado graças a outro conjunto de cartas, a que fomos levados pelo nome de Michel Chodkiewicz.

Apesar da correspondência entre Guimarães Rosa e Villard não explicitar quem seria Chodkiewicz, pode-se facilmente deduzir que se trata do editor da Seuil responsável pela publicação das obras do escritor na França. Assim, é a ele que Guimarães Rosa se compromete a escrever quando quer confirmar o nome de Villard como tradutor de Primeiras estórias (cf. JGR a JJV, 14/10/1963). É a ele, também, que cabe a decisão sobre a assinatura de um contrato que garantisse à Seuil os direitos sobre Sagarana (cf. JGR a JJV, 14/10/1963). Mas apenas a leitura das cartas que Chodkiewicz trocou com outras pessoas que participaram da aventura literária e tradutória que foi o lançamento de Guimarães Rosa na França dos anos 1960 nos permitiu entender o papel decisivo que desempenhou nessa empreitada. E, também, o modo como Jean-Jacques Villard veio a integrá-la.

\section{Bastidores}

\subsection{Uma decisão editorial}

No final dos anos 1950, mais precisamente em 1958, um dos editores da Seuil, Michel Chodkiewicz, está empenhado em identificar autores brasileiros contemporâneos que possam ser publicados na França. A iniciativa vinha somar-se a um grande movimento que, na Europa e nos Estados Unidos do pós-guerra, voltava-se para a América Latina, buscando conhecer sua cultura, principalmente no que se referia à música e à literatura.

Esse interesse pode ser percebido em filigrana na correspondência entre Guimarães Rosa e J.-J. Villard por meio dos personagens que a povoam. $\mathrm{O}$ caso da Knopf Incorporation é significativo desse movimento no universo norte-americano. A editora, responsável pela publicação dos livros de Guimarães Rosa na América do Norte, é citada nas cartas no momento do lançamento de Grande sertão: veredas nos Estados Unidos e no Canadá (cf. JGR a JJV, 24/04/1963). Na pessoa de seus diretores, Alfred e Blanche Knopf, a editora sempre buscou novos talentos na Ásia e na Europa. Mas foi apenas com o advento da Segunda guerra mundial e com a "Política da boa vizinhança" instaurada pelo governo Roosevelt, que eles se voltam para a América Latina e passam a publicar, entre outros, Jorge Amado e Gilberto Freyre. No universo francês, o nome de Roger Caillois (cf. JGR a Guilherme de Figueiredo, 23/12/1964) nos remete à emblemática coleção "La Croix du Sud" por ele criada em 1951. Especializada na literatura latino-americana, inaugura-se com Ficções de Jorge Luis Borges e publica 
entre outros, nos anos subsequentes, Julio Cortázar, Alejo Carpentier, Augusto Roa Bastos, Rosário Castellanos e os brasileiros Gilberto Freyre, Jorge Amado, Vianna Moog e Graciliano Ramos.

Dentro desse grande movimento de abertura à literatura estrangeira, as Éditions du Seuil desempenharam papel singular. Dirigida por Paul Flamand e Jean Bardet, a então jovem editora caracterizava-se por lançar autores contemporâneos desconhecidos do público, fossem eles franceses ou estrangeiros. Sua política editorial consistia em trabalhar pela divulgação dos escritores que julgavam importantes, cuidando da publicação, se possível, de toda a sua obra. Um exemplo dessa política foi a aposta no poeta americano T. S. Eliot, que cedeu os direitos de publicação de toda a sua obra na França para a Seuil. Em contrapartida, a casa cuidou para que seu nome se consolidasse entre os leitores franceses, assim como fez para o escritor austríaco Robert Musil e seu O homem sem qualidades e para o italiano Giuseppe di Lampedusa e seu O Leopardo, entre muitos outros.

A relação das Éditions du Seuil com seus autores foi sintetizada pelo próprio Paul Flamand em um dos boletins da editora. "A escolha de um manuscrito", diz ele, "não é primordialmente um ato de comércio, ou um lance de dados; é antes de tudo um engajamento pessoal, a aceitação de uma aventura comum" (citado por LACOUTURE, 2010, p. 93). A escolha de um autor implica uma fidelidade do editor com relação a ele, o compromisso de acompanhá-lo junto à crítica e ao público:

Ayant trouvé en son éditeur son premier lecteur, son premier censeur et son premier dévot, le romancier saura que désormais il n'est plus seul face à la critique, face au public, et qu'il y a auprès de lui quelqu'un qui l'a choisi et dont la fidélité ne cesse pas. (citado por LACOUTURE, 2010, p. 95)

Tendo encontrado em seu editor seu primeiro leitor, seu primeiro censor e seu primeiro devoto, o romancista saberá que, a partir de então, não está mais sozinho face à crítica, face ao público, e que existe junto dele alguém que o escolheu e cuja fidelidade não cessa.

A Seuil possuía um Comitê de Leitura, formado por seus principais editores. Era esse Comitê que discutia sobre as obras a serem publicadas. Michel Chodkiewicz fazia parte dele, ao lado de, entre outros, Claude Durand, Jean Cayrol, Paul-André Lesort. Jean Cayrol publicará os textos de Roland Barthes e Philippe Sollers. Claude Durand traduzirá, com sua mulher, Carmen, Cem anos de solidão, lançado pela Seuil em 1968. E Michel Chodkiewicz será, como veremos, a personagem decisiva para a publicação e divulgação da obra de Guimarães Rosa na França dos anos 1960.
O intuito de Chodkiewicz, como ele próprio explicará após ter comprado os direitos para a publicação de Corpo de baile na França, era encontrar entre as obras brasileiras contemporâneas, "livros que fossem ao mesmo tempo representativos do Brasil e suficientemente livres dos particularismos locais para serem classificados entre as obras de classe internacional" (MC a Everaldo Dayrell de Lima, 17/09/1959)2 ${ }^{2}$.

Com esse objetivo, aconselhara-se junto à José Olympio Editora, que lhe indica Grande sertão: veredas e o endereço de Guimarães Rosa, já que os direitos de publicação deveriam ser negociados diretamente com os autores (cf. Livraria José Olympio às Éditions du Seuil, 21/02/1958). Guimarães Rosa já cedera o romance à outra editora e sugere que Chodkiewicz examine Corpo de baile, que muitos críticos consideravam, afirma o escritor, tão bom ou mesmo melhor que Grande sertão: veredas (cf. JGR a MC, 10/11/1958). O editor, que não dominava o português, pede a seus leitores nessa língua que avaliem não apenas Corpo de baile mas também Grande sertão: veredas e Sagarana.

Os relatórios são unânimes. "Estou cada vez mais convencido", diz o avaliador de Sagarana, "que Guimarães Rosa pertence a essa raça de homens capazes de construir uma visão cósmica do universo a partir da vida cotidiana por eles observada". A capacidade de reunir particular e universal é destacada também com relação a Grande sertão: veredas. Guimarães Rosa, diz o leitor do romance, "está na sua terra, perto do mito. Essencialmente ligado a um Brasil cósmico. Não pensemos, por isso, em uma literatura nacionalista, politizável. Guimarães Rosa faz uma espécie de Legenda Áurea do Brasil (...)”. Segundo o relator de Corpo de baile, essa obra seria, por sua vez, uma espécie de Bíblia do Sertão, cujo encanto residiria na perfeita adequação de estilo e matéria; é essa adequação, diz ele, "que universaliza sua literatura, contudo tão brasileira" (MC a JGR, 01/06/1959 - Anexo).

Guimarães Rosa, afirma ainda o parecer sobre Grande sertão: veredas, não é apenas "um escritor exótico, folclórico". Trata-se de "um escritor universal e seus livros passarão (...) para o patrimônio cultural da humanidade". Essa qualidade seria garantia de sucesso comercial e Guimarães Rosa, lançado na Europa, seria um candidato certo ao prêmio Nobel:

Du point de vue commercial "l'opération" Guimarães Rosa n'est pas une aventure, parce que la qualité est toujours une garantie, malgré les efforts de certains éditeurs pour le démentir. A Guimarães Rosa ne lui

\footnotetext{
2 A correspondência de Michel Chodkiewicz e das Éditions du Seuil que citamos neste artigo pertence ao Fundo das Éditions du Seuil, conservado pelo IMEC - Institut Mémoires de l'Édition Contemporaine. Utilizaremos a abreviatura MC para nos referirmos a Michel Chodkiewicz nas citações.
} 
manque qu'un minimum de lancement en Europe, pour être un très sûr candidat au Nobel, par exemple, le reste des conditions, qualité supérieure aux dix derniers Nobels inclus, ne lui manquent pas. (Grande sertão: veredas, relatório de leitura, $\mathrm{s} / \mathrm{d}$ )

Do ponto de vista comercial a “operação" Guimarães Rosa não é uma aventura, porque a qualidade é sempre uma garantia, apesar dos esforços de certos editores para desmentir isso. A Guimarães Rosa falta unicamente um mínimo de lançamento na Europa, para ser um candidato absolutamente certo ao Nobel, por exemplo, o resto das condições, inclusive qualidade superior aos últimos dez nobéis, não lhe faltam.

No final de janeiro de 1959, de posse desses relatórios todos "unanimemente favoráveis" e considerando o livro "como uma das maiores, senão mesmo como a maior das obras brasileiras contemporâneas" (MC a JGR, 26/01/1959), "obra de qualidade excepcional, e de enorme originalidade" (MC a Roger Bastide, 16/01/1959), Chodkiewicz escreve a Guimarães Rosa, dizendo-lhe que os únicos obstáculos à decisão favorável por parte da Seuil estariam ligados à tradução e ao tamanho da obra:

Les seuls obstacles qui puissent s'opposer à une décision positive sont, d'une part, la très grande difficulté de traduire ce texte, dont le riche vocabulaire et la syntaxe très personnelle posent, à chaque instant, des problèmes compliqués et, d'autre part, la longueur de l'œuvre qui risque de limiter le public. (MC a JGR, 26/01/1959)

Os únicos obstáculos que podem se opor a uma decisão positiva são, de um lado, a enorme dificuldade de traduzir esse texto, cujo rico vocabulário e a sintaxe extremamente pessoal colocam, a todo instante, problemas complicados, e, de outro, o comprimento da obra, que pode limitar o público.

Fora Roger Bastide, a quem Chodkiewicz consultara para saber sua opinião sobre Corpo de baile e seu autor, que levantara o problema da tradução:

Je n'ai pas lu Corpo de Baile qui a paru après mon départ du Brésil. Mais j'ai lu le premier livre de João Guimarães Rosa, qui le classait parmi les plus grands écrivains du Brésil. Tous les Brésiliens que j’ai vus depuis sont d'accord pour le considérer comme actuellement le seul très grand. Mais je crois qu'il est très difficile de le traduire; il utilise souvent les procédés de Joyce, c'est-à-dire, qu'il crée des mots nouveaux (j'ai lu une très intéressante étude sur ses règles de fabrication des vocables) et il faudrait trouver un traducteur qui serait capable de transposer cela en français... (Roger Bastide a MC, 20/01/1959)

Não li Corpo de baile que foi publicado após a minha partida do Brasil. Mas li o primeiro livro de João
Guimarães Rosa, que o classificava entre os maiores escritores do Brasil. Todos os brasileiros com quem falei desde então concordam em considerá-lo como atualmente o único muito grande. Mas creio que é muito difícil traduzi-lo; ele usa frequentemente palavras novas (li um estudo muito interessante sobre suas regras de fabricação dos vocábulos) e seria preciso encontrar um tradutor que fosse capaz de transpor isso em francês...

Mas o editor, impressionado com os relatórios de leitura que recebera, convence o Comitê de Leitura da Seuil a publicá-lo. Estava decidido a superar todos os obstáculos e a trabalhar pela literatura de Guimarães Rosa na França. Assim, menos de um mês depois ele volta a escrever ao autor:

Vous savez, maintenant, que nous sommes fermement décidés à publier Corpo de baile. Comprenez qu'il ne s'agit pas, pour nous, d'une décision banale, mais que nous avons le désir de nous engager à fond sur votre nom et sur votre oeuvre. Nous sommes prêts à faire pour vos livres, en France, ce que nous avons déjà fait, avec succès, pour ceux de Robert Musil et de Eliot. Nous savons que nous nous trouvons en face d'une très grande oeuvre - de celles qu'un éditeur n'a pas souvent la chance de rencontrer au cours de sa carrière - et nous sommes résolus à tenter tout ce qu'il sera possible de tenter pour l'imposer en France, et la faire bénéficier de l'audience qu'elle mérite. (MC a JGR, 17/02/1959)

O senhor sabe, agora, que estamos firmemente decididos a publicar Corpo de baile. Entenda que não se trata, para nós, de uma decisão banal, mas que desejamos nos engajar a fundo em seu nome e sua obra. Estamos prontos a fazer pelos seus livros, na França, o que já fizemos, com sucesso, pelos de Robert Musil e Eliot. Sabemos que nos encontramos diante de uma grande obra - dessas que um editor nem sempre tem a oportunidade de encontrar em sua carreira - e estamos resolvidos a tentar tudo o que for possível tentar para impô-la na França, e fazê-la beneficiar da audiência que merece.

As Éditions du Seuil não queriam ser para Guimarães Rosa, como afirma Chodkiewicz na mesma carta, "um editor entre outros", mas "o $\underline{\text { seu }}$ editor". O "engajamento pessoal" para com a obra de Guimarães Rosa estava firmado. O projeto da editora era publicar toda a sua obra, tanto as já escritas como as por escrever, e não foram poucas as vezes que o editor lamentou que Grande sertão: veredas já tivesse sido cedido à outra casa.

Assim, na França, a publicação de Guimarães Rosa derivou de uma decisão editorial firme, de um projeto que pretendia lançar não um livro, mas toda a obra de um autor que, tanto segundo as informações dos leitores 
da editora, quanto de diversos escritores - vimos o depoimento de Roger Bastide - era um dos maiores prosadores contemporâneos. O escritor encontrara, na França, um editor à altura de sua obra. Foi este editor que, como prometido, se engajou a fundo para encontrar quem pudesse realizar, de Corpo de baile, "uma tradução digna desse nome" (MC a Everaldo Dayrell de Lima, 17/09/1959)

\subsection{Mas existiria "um tradutor temerário o suficiente para tentar a aventura"?}

Além de Roger Bastide, outros escritores já haviam afirmado a Chodkiewicz a excelência de Guimarães Rosa, alertando-o, ao mesmo tempo, sobre a dificuldade de transpô-lo para outra língua. Em carta a um dos leitores da Seuil, três meses após o início de sua busca por um tradutor, Chodkiewicz comenta a situação difícil em que se encontra:

Je ne vous cache pas que je suis, pour l'instant, sinon découragé du moins très embarrassé. Cette semaine encore, j'ai vu plusieurs écrivains brésiliens de passage à Paris, qui ont tous applaudi au choix que nous avons fait, mais se sont montrés très pessimistes quant aux possibilités d'adaptation. (MC a Antonio Bandeira, 29/05/1959)

Não escondo que estou, por enquanto, senão desanimado, pelo menos, bem embaraçado. Ainda esta semana, vi vários escritores brasileiros de passagem por Paris, que aplaudiram sem exceção a escolha que fizéramos, mas se mostraram muito pessimistas quanto às possibilidades de adaptação.

O editor escreve também a Guimarães Rosa, relatando o fracasso de suas primeiras experiências: "Todas as pessoas que pressenti, e que fizeram uma breve tentativa (cercando-se dos conselhos de brasileiros competentes) finalmente recuaram diante das dificuldades de seu livro" (MC a JGR, 01/06/1959).

Os que haviam recuado diante da complexidade da tarefa alegam seja sua incapacidade "de manipular a língua francesa com a habilidade com que Guimarães Rosa manipula a nossa" (ALVIM, 1961), seja seu desconhecimento do regionalismo brasileiro e das muitas expressões locais (Pierre Denis a MC, 08/10/1959). Por outro lado, a Seuil recusa outros profissionais seja por considerar sua tradução "muito pesada" e "com verdadeiros erros de francês" (MC a JGR, 01/06/1959); seja por seu "tom demasiadamente literal, demasiadamente escolar", como consta da avaliação de um teste de tradução de 18 de agosto de1959; seja porque apesar do tom "fiel e correto", a tradução "não fazia o leitor sentir suficientemente o grande vento de liberdade e de poesia que sopra através das páginas de Guimarães Rosa" (MC a Olga Obry, 30/12/1959).

Chodkiewicz, porém, não esmorece. Ao recorrer ao adido cultural da Embaixada do Brasil em Paris, diz-lhe que esperava encontrar mais facilmente "um tradutor temerário o suficiente para tentar a aventura", mas que a dificuldade de encontrar a pessoa adequada para tal empresa só o encoraja ainda mais a fazer o impossível para consegui-la. "Estamos mais firmemente resolvidos que nunca", diz ele, "a fazer todo o possível para conseguir editar, em um prazo razoável, uma tradução digna desse nome" (MC a Everaldo Dayrell de Lima, 17/09/1959).

Em meio a essas tentativas, ele recebe uma carta de Jean-Jacques Villard, que se apresenta como "tradutor de inglês, alemão, holandês, espanhol e português ou, mais exatamente, de brasileiro", já tendo traduzido $O$ tempo e o vento de Érico Veríssimo (JJV a MC, 25/11/1959). Talvez o fato de Villard ter precisado que esse livro "apresentava dificuldades certeiras de tradução, muitas palavras de origem espanhola ou guarani, assim como expressões folclóricas que não figuravam em nenhum dicionário" tenha interessado a Chodkiewicz que marca uma entrevista com ele para conversarem a respeito da tradução de uma obra que apresentava, explica-lhe o editor, "dificuldades ainda maiores do que as que o senhor possa ter encontrado traduzindo Érico Veríssimo" (MC a JJV, 01/12/1959).

Em janeiro de 1960, Chodkiewicz comunica ao adido cultural da Embaixada brasileira em Paris ter encontrado o tradutor capaz "de responder às exigências que a adaptação de uma obra assim complexa impõe". A versão que Jean-Jacques Villard fizera de algumas páginas de Corpo de baile haviam agradado ao editor:

Les pages que M. Villard a traduites, à titre d'essai, sont excellentes et je crois pouvoir espérer la publication au début de l'année prochaine d'un premier tome de Corpo de baile. (MC a Everaldo Dayrell de Lima, 07/01/1960)

As páginas que o senhor Villard traduziu, a título de teste, são excelentes e acredito poder esperar a publicação, para o início do ano que vem, de um primeiro tomo de Corpo de baile.

A busca durara quase um ano. Ao contrário do que aconteceu na Alemanha, em que foi o tradutor, Curt Meyer-Clason, que pelejou para encontrar um editor que aceitasse publicar as obras de Guimarães Rosa, na França foi pela vontade de um editor que se encontrou um tradutor para elas. Se na Alemanha "o casamento feliz entre autor e tradutor", para retomar ainda uma vez a expressão de Guimarães Rosa, foi precedido de um longo namoro, na França tratou-se de um casamento arranjado que só depois se tornou paixão. 
O desejo de Guimarães Rosa, expresso em carta a Michel Chodkiewicz, de "poder ser lido, conhecido e amado, na França, pelo maior número possível de pessoas" (JGR a MC, 08/10/1963) realizara-se graças à determinação de um editor, apoiado por um projeto editorial peculiar.

\section{Conclusão}

A exploração das cartas de João Guimarães Rosa com seu tradutor francês, particularmente a confecção das notas, em que buscamos definir o papel que as pessoas e instituições ali citadas desempenharam no processo de publicação de seus livros, nos convidam a pensar a tradução e a recepção de uma obra do ponto de vista sociológico.

De fato, Johan Heibron e Gisèle Sapiro definem a sociologia da tradução e da recepção como a ciência que vai pensar "o conjunto das relações pertinentes no seio das quais as traduções são produzidas e circulam" (HEIBRON e SAPIRO, 2002, p. 4), recusando tanto a hermenêutica, que busca o sentido do texto independentemente das condições sociais que a propiciaram, quanto o determinismo econômico, que assimila o livro a uma mercadoria como outra qualquer.

Isso significa pensar um livro em seu contexto espaçotemporal de produção e recepção e, também, os atores, sejam eles instituições ou indivíduos, que participaram de sua realização: autor, agentes literários, editores, editoras, tradutor, críticos, leitores. E neste artigo, tentamos justamente mostrar o papel fundamental de um editor, Michel Chodkiewicz, de uma editora, a Seuil, e de um tradutor, Jean-Jacques Villard, na publicação de Corpo de baile na França.

Contudo, não devemos esquecer que a ação desses agentes e a força com que se dedicaram às suas tarefas teve como estopim um objeto bem particular e concreto: os livros de Guimarães Rosa. Foi o impacto provocado por Sagarana, Corpo de baile e Grande sertão: veredas nos leitores da Seuil, impacto atestado em seus relatórios de leitura, que deslanchou todo o processo de produção de Corpo de baile e o projeto de publicar o restante da obra ainda disponível do escritor. A busca do tradutor também se baseou nessa impressão deixada pelo original. Era preciso encontrar quem pudesse entregar ao leitor francês um texto legível que, porém, não apagasse a comoção que a escrita de Guimarães Rosa acarretava.

Paulo Rónai diz que "ninguém aceita como tarefa comum a versão de um Grande sertão: veredas" (RÓNAI, 1971) e que só o entusiasmo pelos textos de Guimarães Rosa pode explicar que alguém não recue diante de tal desafio. Em outras palavras, apenas o encontro do tradutor com uma obra permite que ele estabeleça, por intermédio dela, uma relação com o autor. Barthes afirma que é pela mediação das instâncias textuais criadas pela própria escrita literária (BARTHES, 2004) que o autor se relaciona com seu leitor - seja ele somente um leitor, ou um relator de uma editora, ou o próprio editor, ou um tradutor, ou um crítico. Captados pela obra, eles encarnam o leitor ideal ali construído e são, assim, em certa medida criados por ela. Daí a natureza pessoal, para retomar a bela fórmula de Paul Flamand, do compromisso que assumem frente a ela e ao autor.

Dessa maneira, se Corpo de baile só pôde ser lançado na França em razão de condições históricosociais propícias, não é menos verdade que foi o próprio livro que, como desejava Guimarães Rosa, "intrigando o leitor e mexendo com seu subconsciente" (JGR a Edoardo Bizzarri, 18/11/63 - ROSA, 1981, p. 45), aliciou as pessoas capazes de lê-lo, avaliá-lo, editá-lo e traduzi-lo.

\section{Referências}

ALVIM, Gilda Cesário. Guimarães Rosa em francês. Jornal do Brasil, Rio de Janeiro, 22 ago. 1961. Bilhete de Paris. Fundo Guimarães Rosa, Instituto de Estudos Brasileiros, Universidade de São Paulo. Recorte de jornal.

BARTHES, Roland. A morte do autor. In. O rumor da língua. Tradução de Mário Laranjeira. São Paulo: Martins Fontes, 2004.

BASTIDE, Roger. Carta a Michel Chodkiewicz, 20/01/1959. Fundo Seuil do Institut Mémoires de l'Édition Contemporaine (IMEC), Abbaye d'Ardenne.

CHODKIEWICZ, Michel. Carta a Antonio Bandeira, 29/05/1959. Fundo Seuil do Institut Mémoires de l'Édition Contemporaine (IMEC), Abbaye d'Ardenne.

CHODKIEWICZ, Michel. Carta a Everaldo Dayrell de Lima, 17/09/1959. Fundo Seuil do Institut Mémoires de l'Édition Contemporaine (IMEC), Abbaye d'Ardenne.

CHODKIEWICZ, Michel. Carta a Jean-Jacques Villard, 01/12/1959. Fundo Seuil do Institut Mémoires de l'Édition Contemporaine (IMEC), Abbaye d'Ardenne.

CHODKIEWICZ, Michel. Carta a João Guimarães Rosa, 01/06/1959. Fundo Seuil do Institut Mémoires de l’Édition Contemporaine (IMEC), Abbaye d'Ardenne.

CHODKIEWICZ, Michel. Carta a João Guimarães Rosa, 17/02/1959. Fundo Seuil do Institut Mémoires de l'Édition Contemporaine (IMEC), Abbaye d'Ardenne.

CHODKIEWICZ, Michel. Carta a João Guimarães Rosa, 26/01/1959. Fundo Seuil do Institut Mémoires de l'Édition Contemporaine (IMEC), Abbaye d'Ardenne.

CHODKIEWICZ, Michel. Carta a Olga Obry, 30/12/1959. Fundo Seuil do Institut Mémoires de l'Édition Contemporaine (IMEC), Abbaye d'Ardenne.

CHODKIEWICZ, Michel. Carta a Roger Bastide, 16/01/1959. Fundo Seuil do Institut Mémoires de l’Édition Contemporaine (IMEC), Abbaye d'Ardenne. 
DENIS, Pierre. Carta a Michel Chodkiewicz. 08/10/1959. Fundo Seuil do Institut Mémoires de l'Édition Contemporaine (IMEC), Abbaye d'Ardenne.

HEIBRON, Johan, SAPIRO, Gisèle. La traduction littéraire, un objet sociologique. Actes de la recherche en sciences sociales, v. 144, p. 3-5, set. 2002. Disponível em: <http://www.persee. fr/web/revues/home/prescript/article/arss_0335-5322_2002_ num_144_1_2803>.Acesso em 25/10/2013.

LACOUTURE, Jean. Paul Flamand, éditeur. Paris: Éditions des Arènes, 2010.

Livraria José Olympio às Éditions du Seuil, 21/02/1958 Fundo Seuil do Institut Mémoires de l'Édition Contemporaine (IMEC), Abbaye d'Ardenne.

RÓNAI, Paulo. Guimarães Rosa e seus tradutores. O Estado de São Paulo, São Paulo, 10 out. 1971. Suplemento Literário, n. 741 , p. 1.

ROSA, João Guimarães. Carta a Michel Chodkiewicz, 08/10/1963. Fundo Seuil do Institut Mémoires de l'Édition Contemporaine (IMEC), Abbaye d'Ardenne.
ROSA, João Guimarães. Carta a Michel Chodkiewicz, 10/11/1958. Fundo Seuil do Institut Mémoires de l'Édition Contemporaine (IMEC), Abbaye d'Ardenne.

ROSA, João Guimarães. Correspondência com seu tradutor francês, Jean-Jacques Villard. Série Correspondência com Tradutores. Fundo Guimarães Rosa do Instituto de Estudos Brasileiros (IEB), da Universidade de São Paulo, [1961-1967].

ROSA, João Guimarães. Correspondência com seu tradutor italiano, Edoardo Bizzarri. São Paulo: Queiroz; Instituto Cultural Ítalo-Brasileiro, 1981.

VILLARD, Jean-Jacques. Carta a João Guimarães Rosa, 27/07/1961. Arquivo da família de Jean-Jacques Villard.

VILLARD, Jean-Jacques. Carta a Michel Chodkiewicz, 25/11/1959. Fundo Seuil do Institut Mémoires de l'Édition Contemporaine (IMEC), Abbaye d'Ardenne.

Recebido: 30 de outubro de 2013

Aprovado: 22 de novembro de 2013

Contato:mv.aguiar@uol.com.br 